G (HGV) as a new transfusion transmitted agent ${ }^{8}$ is identical with GBV-C.

The blood borne nature of HGV has been clearly demonstrated and there is evidence that it persists. The association of the virus with liver damage is illustrated by raised alanine aminotransferase (ALT) activities and detectable HGV RNA in a number of patients. However, between 40 and $90 \%$ of viraemic subjects have normal ALT. In a significant proportion of patients there is co-infection with $\mathrm{HBV}$ or HCV, or both. The primary manifestations, if any, of $\mathrm{HGV}$ infection may be extrahepatic and liver damage may be the result of co-infection with the hepatitis viruses - or an as yet unidentified hepatotropic agent. The development of sensitive and specific serological tests for GBV-C/HGV, the application of modern virological techniques and histological studies where appropriate, will determine the clinical importance of this newly identified virus.

The alphabet of hepatitis viruses has been extended to $\mathrm{G}$; others may well be awaiting discovery.

JANE N ZUCKERMAN

Senior Clinical Research Fellow

Academic Unit of Travel Medicine and Vaccines,

Royal Free Hospital School of Medicine
Director

ARIE J ZUCKERMAN

WHO Collaborating Centre for Reference

and Research on Viral Diseases,

Royal Free Hospital School of Medicine,

London NW3 $2 P F$

1 Oon C-J, Lim G-K, Ye Z, Goh K-T, Tan K-L, Yo S-L, et al. Molecular epidemiology of hepatitis B virus vaccine variants in Singapore. Vaccine 1995;13:699-702.

2 Carman WF, Thomas H, Zuckerman AJ, Harrison T. Molecular variants of hepatitis B virus. In: Zuckerman AJ, Howard HC, eds. Viral hepatitis: Scientific basis and clinical management. Edinburgh: Churchill Livingstone, 1994: 115-36.

3 Fagan EA, Ellis DS, Tovey GM, Lloyd G, Portmann B, Williams R, et al. Toga-like virus as a cause of fulminant hepatitis attributed to sporadic non-A, non-B. $f$ Med Virol 1989;28:150-5.

4 Deinhardt F, Holmes AW, Capps RB, Popper H. Studies on the transmission of human viral hepatitis to marmoset monkeys. 1. Transmission of disease, serial passages and description of liver lesions. $\mathcal{F}$ Exp Med 1967;125:673-88.

5 Schlauder GG, Dawson GJ, Simons JN, Pilot-Matias TJ, Guiternez RA, Heynen CA, et al. Molecular and serologic analysis in the transmission of the GB hepatitis agents. $\mathcal{F}$ Med Virol 1995;46:81-90.

6 Simons JN, Leary TP, Dawson GJ, Pilot-Matias TJ, Muerhoff AS, Schlauder GG, et al. Isolation of novel virus-like sequences associated with human hepatitis. Nature Med 1995;1:564-9.

7 Leary TP, Muerhoff AS, Simons JN, Pilot-Matias TJ, Erker JC, Chalmers $\mathrm{ML}$, et al. Sequence and genomic organization of GBV-C. A novel member of the Flaviviridae associated with human non-A-E hepatitis. $f$ Med Virol 1996;48:60-7.

8 Linnen J, Wages J, Zhang-Keck Z-Y, Fry KE, Krawczysnki KZ, Alter H, et al. Molecular cloning and disease association of hepatitis $G$ virus: a new transfusion transmissible agent. Science 1996;271:505-9.

\title{
A rational approach to immunohistochemical analysis of malignant lymphomas on paraffin wax sections
}

The recently proposed Revised European-American Lymphoma (REAL) classification ${ }^{1}$ is the first to regard immunophenotyping as an integral part of the process of diagnosing lymphoid tumours, as it permits more objective interpretation of the histological pattern. The usefulness of this approach has been confirmed in the course of a validation study on the REAL classification sponsored by the National Cancer Institute. This validation study showed that the rate of diagnostic consensus for several categories of malignant lymphomas (for example, diffuse large B cell, peripheral $\mathrm{T}$ cell unspecified, anaplastic large cell lymphomas) is notably increased when morphology and phenotypic findings are considered together (Müller-Hermelink $\mathrm{H}-\mathrm{K}$, personal communication). Furthermore, immunohistochemistry provides valuable prognostic and therapeutic information, and contributes to the better understanding of the histogenesis and pathogenesis of lymphoid neoplasms. ${ }^{1}$ In the light of its practical impact, immunohistochemical analysis of malignant lymphomas deserves further attention. In their paper in this issue (p16), Singh and Wright look at the possibility of distinguishing between B-small lymphocytic lymphoma and mantle cell lymphoma via immunohistochemical analysis of routinely processed paraffin wax sections, prompting the following general remarks.

Sample processing is a basic step. Wherever possible, part of the sample should be kept frozen in order to optimise preservation of both molecules and nucleic acids. ${ }^{2}$ However, as most laboratories are not equipped for cryo- preservation, immunophenotypic analysis of paraffin wax sections is the next logical step. ${ }^{2}$

Fixation is a crucial step for routine samples: we recommend incubation in $10 \%$ buffered formalin at room temperature for six (gastric biopsy specimens) to 24 (2-3 $\mu \mathrm{m}$ thick sections of lymph node or spleen) hours. ${ }^{2}$ This ensures homogeneous fixation of all the parts of the specimen. For bone marrow needle biopsy specimens, we recommend fixation in $\mathrm{B} 5$ for two and a half hours, followed by a 30 minute wash in $70 \%$ alcohol and decalcification in DECAL for two and half hours. ${ }^{2}$ All of these procedures result in optimal preservation of cytological details and homogeneous immunostaining of different parts of the same specimen.

Other important points are (1) the method chosen for antigen retrieval; (2) the sensitivity of the detection system; and (3) the use of semi/automated immunohistochemical techniques. With regard to antigen retrieval, the introduction of heat-based techniques has greatly improved the possibility of detecting epitopes masked by fixation: however, different approaches have been proposed in the literature, with varying efficacy (for a comprehensive review see Cattoretti et $a l^{3}$ ). We recently compared the main variables in antigen retrieval techniques: different buffers; proteolytic enzymes versus heat-based antigen retrieval; and microwaving versus pressure cooking (Pileri et al, manuscript submitted). The aim of our study was to optimise antigen retrieval at our centre, which routinely receives heterogeneously treated material for consultation. 
Table 1 Phenotypic profile of precursor B-and T-cell neoplasms versus that of acute non-lymphoid leukaemias

\begin{tabular}{|c|c|c|c|c|c|c|c|c|}
\hline & $B-L A L$ & $T-L A L$ & $M 1 / M 2$ & M3 & M4 & $M 5^{\star}$ & M6 & M7 \\
\hline CD34 & $+1-$ & $-1+$ & $-1+$ & - & - & - & - & - \\
\hline CD79a & + & - & - & - & - & - & - & - \\
\hline CD20 & $-1+$ & - & - & - & - & - & - & - \\
\hline CD45RA & + & $+1-$ & - & - & - & - & - & - \\
\hline CD45RO & - & $+1-$ & $+/-$ & $+/-$ & $+/-$ & $+1-$ & - & - \\
\hline $\mathrm{CD} 43$ & $+/-$ & + & + & + & $+/-$ & $+/-$ & $+/-$ & - \\
\hline CD3 & - & + & - & - & - & - & - & - \\
\hline CDla & - & $-1+$ & - & - & - & - & - & - \\
\hline Myeloperoxidase & - & - & + & + & $+/-$ & - & - & - \\
\hline CD15 & - & - & - & + & $-1+$ & - & - & - \\
\hline Neutrophilic elastase & - & - & $+/-$ & + & $+/-$ & - & - & - \\
\hline CD68/ KP1 & - & - & + & + & + & + & - & $+/-$ \\
\hline CD68/ PGM1 & - & - & - & - & $+/-$ & + & - & e \\
\hline Glycophorin A & - & - & - & - & - & - & + & - \\
\hline Glycophorin C & - & - & - & - & - & - & + & - \\
\hline CD61 & - & - & - & - & - & - & - & + \\
\hline Factor VIII-related antigen & - & - & - & - & - & - & - & + \\
\hline
\end{tabular}

B-LAL = precursor B-lymphoblastic leukaemia/lymphoma; T-LAL = precursor T-lymphoblastic leukaemia/lymphoma; $\mathrm{M1}-\mathrm{M} 7$ = non-lymphoid leukaemias according to the FAB classification.

$+=70-100 \%$ of positive cases; $+/-=40-70 \%$ of positive cases; $-/+=20-40 \%$ of positive cases; $\mathrm{e}=10-20 \%$ of positive cases; $-=$ less than $10 \%$ of positive cases *The phenotypic profile of M5 is the same as that of malignant histocytosis.

Table 2 Phenotypic profile of peripheral B-cell lymphomas

\begin{tabular}{|c|c|c|c|c|c|c|c|c|c|c|c|c|}
\hline & $C D 79 a$ & $C D 20$ & $\begin{array}{l}C D 45 R \\
\text { KiB3 }\end{array}$ & $C D 5^{*}$ & $C D 43$ & $C D 23$ & $\begin{array}{l}C D 68, \\
K P 1\end{array}$ & $C D 30$ & $S I g$ & $C I g$ & $b c l 2$ & Other \\
\hline$\overline{\mathrm{B}-\mathrm{CLL}}$ & + & + & $+1-$ & + & + & + & - & - & $+w$ & - & + & \\
\hline Immunocytoma & + & + & $-/+$ & - & $-1+$ & - & e & $\mathrm{e}$ & + & + & + & \\
\hline MCL & + & + & - & + & $+1-$ & - & - & - & + & - & + & Cyclin D1 \\
\hline FCL & + & + & $+1-$ & - & - & - & - & $\mathrm{e}$ & + & - & + & \\
\hline MZL & + & + & + & - & $-1+$ & - & $+/-$ & - & + & $-1+$ & + & DBA $44+/-$ \\
\hline $\mathrm{HCL}$ & + & + & + & - & - & - & + & - & + & - & + & DBA 44+ \\
\hline MM & $+/-$ & - & + & - & $+1-$ & - & - & $+/-$ & - & + & + & $\mathrm{EMA}+\mathrm{CD} 38+$ \\
\hline DLBCL & + & + & $+/-$ & - & $-1+$ & - & - & $-/+$ & $-1+$ & $-/+$ & $+1-$ & \\
\hline PMBCL & + & + & + & - & - & - & - & $+1-$ & - & $\mathrm{e}$ & $+/-$ & \\
\hline $\begin{array}{l}\text { Burkitt } \\
\text { lymphoma }\end{array}$ & + & + & + & - & - & - & - & - & + & $-1+$ & + & \\
\hline $\begin{array}{l}\text { Burkitt-like } \\
\text { lymphoma }\end{array}$ & + & + & + & - & - & - & - & - & $+/-$ & $-1+$ & + & \\
\hline
\end{tabular}

B-CLL = B-cell chronic lymphotytic leukaemia; $\mathrm{MCL}=$ mantle cell lymphoma; $\mathrm{FCL}=$ follicle centre lymphoma; $\mathrm{MZL}=\mathrm{marginal}$ zone lymphoma; $\mathrm{HCL}=$ hairy cell leukaemia; $\mathrm{MM}=$ multiple myeloma/plasmacytoma; $\mathrm{DLBCL}=$ diffuse large $\mathrm{B}$-cell lymphoma; $\mathrm{PMBCL}=$ primary mediastinal $\mathrm{B}-$ cell lymphoma;

EMA $=$ epithelial membrane antigen.

$+=70-100 \%$ of positive cases; $+/-=40-70 \%$ of positive cases; $-l+=20-40 \%$ of positive cases; $\mathrm{e}=10-20 \%$ of positive cases; $-=$ less than $10 \%$ of positive cases; $\mathrm{w}=$ weak.

^Detectable using a highly sensitive procedures on routine sections from briefly fixed samples.

Table 3 Phenotypic profile of the main categories of peripheral T-cell lymphoma

\begin{tabular}{|c|c|c|c|c|c|c|c|c|c|c|}
\hline & $C D 45$ & $C D 3$ & $C D 8$ & $C D 43$ & $C D 45 R O$ & $C D 30$ & $C D 56$ & CD57 & $C D 15$ & $E M A$ \\
\hline T-CLL & + & + & $-1+$ & + & + & - & - & - & - & - \\
\hline LGLL-TC & + & + & + & + & + & - & - & $+1-$ & - & - \\
\hline LGLL-NK & + & - & $+/-$ & + & + & - & $+1-$ & $+1-$ & - & - \\
\hline $\mathrm{MF} / \mathrm{SS}$ & + & + & e & + & + & - & - & - & - & - \\
\hline PTCL & + & $+1-$ & $-1+$ & $+/-$ & $+/-$ & $-1+$ & - & - & - & - \\
\hline AILD & + & + & $-/+$ & + & + & e & - & - & - & - \\
\hline ALCL & $+1-$ & $-1+$ & e & $-1+$ & $-1+$ & + & - & - & $-1+$ & $+1-$ \\
\hline
\end{tabular}

T-CLL = T-cell chronic lymphocytic leukaemia; LGLL-TC = large granular lymphocyte leukaemia/T-cell type; LGLL-NK = large granular lymphocyte leukaemia/ natural killer cell type; MF/SS = mycosis fungoides/Sézary syndrome; PTCL = peripheral T-cell lymphoma; AILD = angioimmunoblastic lymphoma; ALCL = anaplastic large cell lymphoma; EMA = epithelial membrane antigen.

$+=70-100 \%$ of positive cases; $+/-=40-70 \%$ of positive cases; $-/+=20-40 \%$ of positive cases; $\mathrm{e}=10-20 \%$ of positive cases; $-=$ less than $10 \%$ of positive cases.

Staining by only one of the 60 antibodies studied was not improved by use of antigen retrieval techniques. Five antibodies gave optimal results after digestion of sections with $0.1 \%$ protease $\mathrm{XIV}$ at $37^{\circ} \mathrm{C}$ for five minutes, and 54 by boiling sections in $1 \mathrm{mM}$ EDTA ( $\mathrm{pH} 8.0)$ in a pressure cooker for 90 seconds. The latter approach resulted in reproducible staining with, for example, CD23 and CD30 which may give false negative results in poorly fixed material.

With regard to the detection method, the multilayer alkaline phosphatase anti-alkaline phosphatase (APAAP) technique, and the labelled streptavidin biotin and the streptavidin biotin complex methods are equally effective. Only the newly proposed EnVision-Plus system is three to four times more sensitive (Pileri SA, unpublished observations). It should be noted that in bone marrow, where the peroxidase activity of eosinophils cannot be abolished, the APAAP technique is the method of choice. ${ }^{2}$

Automation of immunostaining also facilitates standardisation by improving laboratory efficiency, ensuring homogeneous distribution of reagents throughout the slides, and by reducing the number of tests that need to be repeated and the workload of the technical staff.

As a result of these advances/improvements, routinely processed sections can now be stained with large panels of antibodies, facilitating the diagnosis of different lymphoma types, the distinction between myeloid and lymphoid acute leukaemias, and the identification of biopathological markers (tables 1-4). Nevertheless, some markers, such as CD5, still give variable results, as underlined by Singh and Wright in their paper and observed by our group with other CD5 antibodies. In particular, the preservation of this 
Table 4 Phenotypic profile of the subtypes of Hodgkin's disease

\begin{tabular}{llllll}
\hline & $L P$ & $N S$ & $M C$ & $L D$ & LRCHD \\
\hline LCA & + & - & - & - & - \\
CD30 & $+/-$ & + & + & + & + \\
CD15 & - & $+/-$ & $+/-$ & $+/-$ & $+/-$ \\
EMA & $+/-$ & - & - & - & - \\
CD20 & + & $-1+$ & - & - & - \\
CD79a & + & $-1+$ & - & - & - \\
CD3 & $-\star$ & $-l+$ & - & - & - \\
CD43 & - & $-1+$ & - & - & - \\
CD45RO & - & $-1+$ & - & - & - \\
LMP-1 & - & $-l+$ & $+/-$ & $-1+$ & $-1+$ \\
\hline
\end{tabular}

LP = lymphocyte predominant Hodgkin's disease; NS = nodular selerosis Hodgkin's disease; $\mathrm{MC}=$ mixed cellularity Hodgkin's disease; $\mathrm{LD}=$ lymphocyte depleted Hodgkin's disease; LRCHD = lymphocyte-rich classic Hodgkin's disease.

$+=70-100 \%$ of positive cases; $+/-=40-70 \%$ of positive cases; $-1+=20-40 \%$ of positive cases; $-=$ less than $10 \%$ of positive cases.

$\star$ Rosettes around popcorn cells.

antigen may require very brief fixation: in a previous study, we achieved optimal detection of CD5 only in tissues fixed in formalin for six hours at most. ${ }^{4}$ However, it is quite likely that these limitations will be soon overcome by further improvements in antigen retrieval techniques and the advent of more sensitive detection methods, of which the catalysed signal amplification technique seems to be the most promising. ${ }^{5}$

Supported by grants from the Italian Association for Cancer Research (AIRC), Milan, and the Ministry of University and Scientific and Technological Research (MURST), Rome.

S A PILERI

E SABATTINI

Second Service of Pathological Anatomy and Haematopathology Unit,

Bologna University,

S. Orsola Hospital,

Via Massarenti 9,

40138 Bologna,

Italy

1 Harris N, Jaffe E, Stein H, Banks P, Chan J, Cleary M, et al. A Revised European-American Classification of lymphoid neoplasms: a proposal from the International Lymphoma Study Group. Blood 1994;84:1361-92.

2 Falini B, Pileri S, Martelli MF. Histological and immunohistological analysis of human lymphoma. Crit Rev Oncol Hematol 1989;9:351-419.

3 Cattoretti G, Suurmeijer AJH. Antigen unmaking on formalin-fixed paraffin-embedded tissues using microwaves: a review. Adv Anat Pathol paraffin-em

4 Cattoretti G, Pileri S, Parravicini C, Becker MHG, Poggi S, Bifulco C, et al. Antigen unmasking on formalin-fixed, paraffin-embedded tissue sections. $\mathcal{F}$ Pathol 1993;171:83-9.

5 Bobrow MN, Harris TD, Schaughnessy KJ, Litt KJ. Catalyzed reporter deposition, a novel method of signal amplification: application to imunoassays. F Immunol Methods 1989;125:279-85. 